\title{
Autokinetic word writing (AWT) and field-dependence'
}

\section{GLEN M. VAUGHT AND WILLIAM HUNTER ${ }^{2}$}

Thirty males and 30 females were divided into field independent (FI) and field dependent (FD) subgroups based on rod-and-frame test (RFT) performance. All Ss were administered the autokinetic word test (AWT) with latency of response and number of words reported constituting the response measures. FI Ss were significantly quicker to respond than FD Ss although there was no difference in the number of words reported.

In a study by Rechtschaffen \& Mednick (1955) it was found that Ss were able to report words being "written" by a standard autokinetic light source. The autokinetic word technique (AWT), as it was called, differs from the typical autokinetic situation in that Ss are told that words are written by the moving light and that they are to report the words being written. Later investigation (Mednick, Harwood, \& Wertheim, 1957) demonstrated that the number and amount of time taken to report words in the AWT was dependent on whether these words were loaded or neutral as measured by the Minnesota standardization of the Kent-Rosanoff Word Association Test. This latter study included a means of introducing both loaded and neutral words into the Ss' response sets via verbal instruction.

Witkin, Dyk, Faterson, Goodenough, \& Karp (1962) have reported a study by Mednick and Shaffer (personal communication to Witkin from Mednick) in which "field-dependent subjects, as established by performance in the embedded-figures test (EFT) tended to see more 'words' than independent subjects, as expected $(r=.30, p<.05) . "$ These data have been construed as reflecting differences between fielddependent and -independent $S$ s in ability to function apart from some frame of reference provided by the experimenter (Witkin et al, 1962, p. 151).

In view of the paucity of research in this specific area, the present study sought to replicate the work of Mednick and Shaffer by using the rod-and-frame test (RFT) as a measure of field-dependence, and by using both number of words and time to respond as dependent variables. In addition, the present study provided a means of investigating possible sex differences. Elfner \& Page (1964) have reported, for example, that latency of autokinesis is significantly longer for women than for men.

\section{Method}

The Ss, 30 male and 30 female introductory psychology students from Albion College, were selected from a pool of Ss who had previously gone through the RFT procedure. Each group of males and females was further divided into subgroups of 15 based on RFT performance. Table 1 shows the mean scores for each identity group.

For AWT, all Ss were seated in a totally darkened room approximately $8 \mathrm{ft}$. from the AWT light source which was emitted from a $10-\mathrm{W}$ bulb placed in a lightproof box (15 in. $x 5$ in. $x \quad 9-1 / 2$ in.) with a $1-\mathrm{mm}$ aperature. The Ss were given a set of standard instructions which indicated that this was a test of their ability to perceive words being written by a pin point of light. Each $S$ was encouraged to guess at what word(s) was being written by the light, but only the phrases "very good" and "you're doing fine" were used to encourage the Ss, after Rechtschaffen \& Mednick (1955). The Ss participated in two 5-min. trials with a 1-min. rest period between trials. In order to insure full transcription of the responses, a tape recorder was employed and placed well behind the Ss with the microphone attached to the chair. The data were collected and analyzed via two separate analyses of variance, i.e., sex by field-dependence for latency (time of first response) and number of responses (words) as well.

\section{Results and Discussion}

Table 1 shows the mean number of words reported in the AWT situation for all Ss. The results of a sex by field-dependence analysis of variance for number of words reported failed to show any significant differences among the groups. Neither sex of the $S$ nor field-dependence made a difference in the number of words reported. Thus, the present data failed to replicate the Mednick and Shaffer finding that fielddependent Ss see more words than independent Ss under AWT instructions.

An analysis of variance for latency scores produced a significant overall difference between field-independent $(\bar{X}=371.63 \mathrm{~min}$.$) and the field-dependent (\bar{X}=$

Table 1. Mean Scores for all Groups Including RFT,

Number of Words, and Latency of Response in Min.

\begin{tabular}{ccccc} 
& N & RFT & $\begin{array}{c}\text { No. of } \\
\text { Words }\end{array}$ & $\begin{array}{c}\text { Response } \\
\text { Latency }\end{array}$ \\
\hline Males & 30 & & & \\
FI & 15 & 2.02 & 1.67 & 387.80 \\
FD & 15 & 13.86 & 1.40 & 515.87 \\
Femoles & 30 & & & \\
FI & 15 & 2.83 & 2.33 & 355.47 \\
FD & 15 & 20.30 & 1.80 & 429.80 \\
\hline
\end{tabular}


472.83 min.) groups $(p<.05)$. These data show that field-independent Ss were quicker to report words being written under AWT instructions than were the field-dependent Ss even when the number of words reported did not differ. Further analysis of the latency means presented in Table 1 via Duncan's multiple range test, showed that both the field-independent males and females took significantly less time to report words than did field-dependent males $(p<.05)$. The present findings suggest that level of fielddependence may not affect the number of words reported in the AWT situation. Rather, the relationship between AWT and field-dependence is more adequately viewed in the latency measure. This reasoning would seem consistent with previous work (Vaught, 1965; Witkin et al, 1962) in which the field-independent Ss would be expected to be less resistant to AWT and more likely to comply with the demands of the experimental task. In this frame of reference complying need not connote yielding to conformity. It may be that field-independent Ss are quicker to respond because they are less threatened by the experimental instructions, in addition to being more open to new experiences.

It is also interesting to note that there were no sex differences for either measure of AWT. This finding is in contrast to the work of Elfner \& Page (1964).
There are two possible explanations: first, the AWT is not strictly comparable with the usual measures of autokinesis; and second, there is some evidence (Vaught, 1965) suggesting that Ss with similar RFT scores behave in a similar way independent of sex. To put it another way, similar "cognitive styles" tend to mask sex differences.

\section{References}

Elfner, L., \& Page, H. Autokinetic movement as a function of lightdark-ratio (LDR). Psychon. Sci., 1964, 1, 59-60.

Mednick, S., Harwood, A., \& Wertheim, J. Perception of disturbing and neutral words through the autokinetic word technique. $J$. abnorm. soc. Psychol., 1957, 55, 267-268.

Mednick, S., \& Shaffer. Personal communication to Witkin, p. 151 , in Witkin et al., 1962.

Rechtschaffen, A., \& Mednick, S. The autokinetic word technique. J. abnorm. soc. Psychol., 1955, 51, 346.

Vaught, G. M. The relationship of role identification and ego strength to sex differences in the rod-and-frame test. J. Pers., $1965,33,271-283$.

Witkin, H. A., Dyk, R. B., Faterson, H. F., Goodenough, D. R., \& Karp, S. A. Psychological differentiation. New York: Wiley, 1962.

\section{Notes}

1. This research was partially supported by an undergraduate research participation grant, GY-196, from the National Science Foundation.

2. The junior author is now at Boston University. 